\title{
Antioxidant Activity of Four Endemic Stachys Taxa
}

\author{
Jelena Kukić, ${ }^{a}$ Silvana Petrović, ${ }^{*, a}$ and Marjan Niketić ${ }^{b}$ \\ ${ }^{a}$ Institute of Pharmacognosy, Faculty of Pharmacy, Belgrade University; Vojvode Stepe 450, 11221 Belgrade: and \\ ${ }^{b}$ Natural History Museum; Njegoševa 51, 11000 Belgrade, Serbia and Montenegro. \\ Received July 13, 2005; accepted January 12, 2006
}

\begin{abstract}
Methanol extracts of aerial flowering parts of four endemic Stachys taxa: $S$. anisochila Vis. et Pančıć, $S$. beckeana Dörfler \& HaYek, $S$. plumosa Griseb. and $S$. alpina L. ssp. dinarica Murb. were investigated on their antioxidant activity. The extracts were studied for total antioxidant activity (TAA), along with 1,1-diphenyl 2picryl hydrazyl (DPPH) and OH radical scavenging activity, and lipid peroxidation (LP). High correlations between total phenolics content, TAA and scavenging DPPH radical indicate that polyphenols are the main antioxidants. All Stachys extracts, with the exception of $S$. plumosa, exhibited high anti-DPPH activity $\left(\mathrm{IC}_{50}<50 \mu \mathrm{g} / \mathrm{ml}\right)$. In concentration range from 6.25 to $50 \mu \mathrm{g} / \mathrm{ml}$, all extracts scavenged $\mathrm{OH}$ radical above $40 \%$, with maximal inhibitions for $S$. anisochila, $S$. alpina ssp. dinarica and $S$. beckeana extracts of $50.22 \%, 50.94 \%$ and $64.97 \%$, respectively. Only $S$. plumosa extract achieved maximal activity of $60.67 \%$ at $100 \mu \mathrm{g} / \mathrm{ml}$. As for $L P$, $I_{50}$ values for $S$. beckeana and $S$. alpina ssp. dinarica extracts were 25.07 and $49.00 \mu \mathrm{g} / \mathrm{ml}$, respectively, while $S$. anisochila and $S$. plumosa extracts did not reach $50 \%$ of LP inhibition.
\end{abstract} tion

Key words Stachys; polyphenol; antioxidant activity; 1,1-diphenyl 2-picryl hydrazyl (DPPH); hydroxyl radical; lipid peroxida-

Free radicals are constantly formed in the human body, but defense mechanisms such as enzymes (glutathione peroxidase, catalase, superoxid dismutase), glutathion, ferritin and others, neutralise them and maintain the balance. ${ }^{1)}$ Large production of some free radicals in the organism, particularly reactive oxygen species (ROS) and their high activity leads to oxidative stress, condition in which endogenous antioxidant mechanisms are insufficient for scavenging ROS. Oxidative stress is considered to be substantial, if not crucial, in initiating and developing of many conditions and diseases of modern time: inflammation, autoimmune diseases, cataract, cancer, Parkinson's disease, artherosclerosis and ageing. ${ }^{2)}$

Having all that in mind, it is reasonable to believe that exogenous antioxidants could play important role in preventing oxidative damage in cells and tissues, by means of scavenging ROS. Vitamin $\mathrm{C}$, tocopherols, carotenoids, some synthetic substances (BHA, BHT) have been evidenced as antioxidants and are widely used in many areas of human life. Since synthetic antioxidants have shown some toxic effects, investigations of antioxidants are now focused on naturally occurring substances, especially plant polyphenols. This large group of second plant metabolites includes: flavonoids, phenolic acids, tannins and others. In spite of large structure diversity they all share the same chemical pattern - one or more phenolic groups, for which they react as hydrogen donors and in that way neutralize ROS. Many studies have proven antioxidant and free radical scavenging activity of various polyphenols. ${ }^{3)}$ It was comparable with classic antioxidants, and in some cases this activity was much higher. Polyphenols also possess many biological effects and these are generally attributed to their antioxidant activities in scavenging free radicals, inhibition of peroxidation and chelating transition metals. ${ }^{4,5}$

Stachys species are traditionally used in different conditions: headache, neuralgia, nervous conditions, as tonic at dyspepsia and for treating wounds and skin inflammation, ${ }^{6}$ as astringent and antidiarrheal. ${ }^{7}$ In pharmacological studies Stachys species showed variety of effects: anti-inflammato- ry, ${ }^{8,9)}$ antibacterial, ${ }^{10,11)}$ anti-nephritic ${ }^{12-14)}$ and anxiolitic. ${ }^{15)}$ Methanol extract of $S$. spruneri showed antioxidant activity similar to $\alpha$-tocopherol, ${ }^{16)}$ while ethanol extract of $S$. sylvati$c a$ had low anti-ABTS activity. ${ }^{17)}$ Phytochemical studies of Stachys species revealed the presence of several secondary plant metabolites: different polyphenols (flavonoids, tannins, phenolic acids, phenylethanoid glycosides), iridoids, terpenoids and sterols. ${ }^{8,9,18)}$

This work deals with antioxidant activity of four Balkan endemic Stachys taxa: S. anisochila VIS. et PANčrć, S. beckeana Dörfler \& HAYEK, S. plumosa Griseb. and S. alpina L. ssp. dinarica MurB. All of them are perennial, herbaceous plants. S. beckeana is endemic Illyrian (Dinaric) species, which inhabits Dinaric Mountains of Balkan Peninsula (N Albania, Montenegro, Herzegovina, S Bosnia). S. anisochila is also Illyrian endemic (W Serbia, Bosnia, Herzegovina and Albania; data for Bulgarian flora are doubtful and still unchecked). In contrast to $S$. beckeana it inhabits lower mountain areas and gorges in the north. Both species belong to very polymorphic $S$. recta L. complex. $S$. plumosa is endemic Moesian-Scardo-Pindhic species and grows on dry pastures and mountain rocks in central and southeastern parts of Balkan Peninsula (SE Serbia, Macedonia, W Bulgaria and N \& C Greece). ${ }^{19)}$ S. alpina belongs to the polymorphic $S$. germanica L. complex. S. alpina ssp. dinarica MURB. is endemic for Balkan Peninsula (Croatia, Bosnia and Herzegovina, Montenegro, Serbia and SW Bulgaria). In contrast to the typical subspecies, it mostly grows at higher altitudes, on mountain pastures and meadows. ${ }^{19-21)}$

\section{MATERIALS AND METHODS}

Chemicals 1,1-Diphenyl 2-picryl hydrazyl (DPPH), Folin-Ciocalteu reagent and 2,4,6-tripyridyl-s-triazine (TPTZ) were obtained from Sigma Chemical Co. (St. Louis, U.S.A.); thiobarbituric acid (TBA) from Merck (Darmstadt, Germany); trichloroacetic acid (TCA), ethylenediaminetetraacetic acid (EDTA) and L-ascorbic acid from Lachema 
(Neratovice, Czech Republic); all other reagents used were of analytical grade.

Plant Material and Extraction Aerial flowering parts of plants were collected from natural populations as follows: S. anisochila in gorge of Beli Rzav (W Serbia) in June 2003; $S$. beckeana from Mt. Durmitor (Montenegro) in August 2003; S. plumosa in Jelašnička klisura gorge (SE Serbia) in June 2002; S. alpina ssp. dinarica on Mt. Jahorina (Bosnia and Herzegovina) in July 2004. Voucher specimens are deposited in Herbarium collection of Natural History Museum in Belgrade (BEO - ko620041/4, ko820033/6, ko320025/6 and ko720049/83, respectively). Plant material was air dried at room temperature and finely grounded. Each sample was bimacerated with chloroform ( 3 and $2 \mathrm{~d}$; plant material : solvent ratio $=1: 7)$. The marc was further extracted in the same manner with methanol. Solvent was evaporated under reduced pressure and obtained dry methanol extracts were used for all investigations.

Thin-Layer Chromatography Fifty microliters of each extract dissolved in methanol $(1 \%, \mathrm{w} / \mathrm{v})$ was applied on silica gel plates (Merck) and developed in system ethyl acetate-acetic acid-formic acid-water (100:11:11:27, $\mathrm{v} / \mathrm{v} / \mathrm{v} / \mathrm{v})$. Flavonoids were detected by spraying with $1 \% 2-$ aminoethyldiphenyl borate solution in methanol followed by $5 \%$ poly-ethylene glycol 4000 in absolute ethanol at $365 \mathrm{~nm}^{22)}$ DPPH test performed directly on TLC plates (0.2\% DPPH in methanol used as spray reagent) revealed contributions to the antioxidant activity of different compounds separately. ${ }^{23,24)}$

Determination of Total Phenolics Total phenolics were determined using Folin-Ciocalteu reagent as previously described, ${ }^{25)}$ with slight modifications. $100 \mu \mathrm{l}$ of the extract $(1 \mathrm{mg} / \mathrm{ml})$ dissolved in methanol was mixed with $750 \mu \mathrm{l}$ of Folin-Ciocalteu reagent (previously diluted 10-fold with distilled water) and allowed to stand at $22^{\circ} \mathrm{C}$ for $5 \mathrm{~min} ; 750 \mu \mathrm{l}$ of $\mathrm{Na}_{2} \mathrm{CO}_{3}(60 \mathrm{~g} / \mathrm{l})$ solution was added to the mixture. After $90 \mathrm{~min}$ the absorbance was measured at $725 \mathrm{~nm}$. Results were expressed as catechin equivalents.

FRAP Assay Total antioxidant activity (TAA) was investigated using Ferric Reducing Antioxidant Power (FRAP) assay, in which reductants in the sample reduce $\mathrm{Fe}^{3+}$-TPTZ complex, present in stoichiometric excess, to the blue colored ferrous form, with an increase in absorbance at $593 \mathrm{~nm} .{ }^{26,27)}$ FRAP reagent was freshly prepared by mixing $25 \mathrm{ml}$ acetate buffer ( $300 \mathrm{~mm}, \mathrm{pH} 3.6), 2.5 \mathrm{ml}$ TPTZ solution $(10 \mathrm{~mm}$ TPTZ in in $40 \mathrm{mmol} / \mathrm{l} \mathrm{HCl})$ and $2.5 \mathrm{ml} \mathrm{FeCl} 3(20 \mathrm{~mm})$ water solution. $150 \mu \mathrm{l}$ of each sample $(1 \mathrm{mg} / \mathrm{ml})$ dissolved in methanol was added in $4.5 \mathrm{ml}$ of FRAP reagent, stirred and after 5 min absorbance was measured at $593 \mathrm{~nm}$, using FRAP working solution as blank. Calibration curve of ferrous sulfate $(100-1000 \mu \mathrm{mol} / 1)$ was used, and results were expressed in $\mu \mathrm{mol} \mathrm{Fe}{ }^{2+} / \mathrm{mg}$ dry weight extract. The relative activity of the samples was compared to L-ascorbic acid.

DPPH Radical Assay All extracts were dissolved in methanol. An aliquot of this solution was mixed with $1 \mathrm{ml}$ of $0.5 \mathrm{~mm}$ DPPH in methanol, and final volume adjusted up to 5 $\mathrm{ml}$. Final concentrations of the extracts were in a range from $5-200 \mu \mathrm{g} / \mathrm{ml}$. Mixtures were virgously shaked and left $30 \mathrm{~min}$ in dark. Absorbance was measured at $517 \mathrm{~nm}$ using methanol as blank. $1 \mathrm{ml}$ of $0.5 \mathrm{~mm}$ DPPH dilluted in $4 \mathrm{ml}$ of methanol was used as control. ${ }^{24)}$ Inhibition of DPPH radical was calculated using the equation: $\mathrm{I}(\%)=100 \times\left(A_{0}-A_{\mathrm{s}}\right) / A_{0}$, where $A_{0}$ is the absorbance of the control (containing all reagents except the test compound), and $A_{\mathrm{s}}$ is the absorbance of the tested sample. The $\mathrm{IC}_{50}$ value represented the concentration of the extract that caused $50 \%$ inhibition.

2-Deoxyribose Assay The 2-deoxyribose method was used for determining the scavenging effect on hydoxyl radical. Investigated extracts were applied in different concentrations $(6.25-200 \mu \mathrm{g} / \mathrm{ml})$. Each reaction mixture contained the following reagents, in the final concentrations stated: $\mathrm{FeCl}_{3}(100 \mu \mathrm{M})$, EDTA $(100 \mu \mathrm{M}), \mathrm{H}_{2} \mathrm{O}_{2}(2.2 \mathrm{~mm})$, 2-deoxyribose $(2.5 \mu \mathrm{M})$, L-ascorbic acid $(100 \mu \mathrm{M})$. Phosphate buffer $(\mathrm{pH}=7.4, I=0.1)$ was added up to a final volume of $4 \mathrm{ml}$. The mixtures were incubated $1 \mathrm{~h}$ at $37^{\circ} \mathrm{C}$, then $1 \mathrm{ml}$ of $1 \%$ (w/v) thiobarbituric acid (TBA) in $0.05 \mathrm{M} \mathrm{NaOH}$ and $1 \mathrm{ml}$ of $2.8 \%(\mathrm{w} / \mathrm{v})$ trichloroacetic acid (TCA) were added in each mixture and heated $15 \mathrm{~min}$ at $100^{\circ} \mathrm{C}$. After cooling on ice absorbance was measured at $532 \mathrm{~nm}^{28)}$ Inhibition of 2-deoxyribose degradation in percents was calculated in the following way: $\mathrm{I}(\%)=100 \times\left(A_{0}-A_{\mathrm{s}}\right) / A_{0}$, where all symbols have the same meaning as in DPPH radical assay.

TBA Test Lipid peroxidation (LP) was measured using preparation of liposomes containing $0.03 \mathrm{~g}$ lecithin $/ \mathrm{ml}$. Liposomes were prepared from the commercial preparation "Lipotech 10", which contains $10 \%$ of lecithin, diluting it with distilled water in ultrasonic bath for $30 \mathrm{~min}$. Reaction mixture contained $20 \mu \mathrm{l} \mathrm{FeSO}_{4}(0.075 \mathrm{M}), 50 \mu \mathrm{l}$ of liposome suspension, $10 \mu \mathrm{l}$ of extract dissolved in $\mathrm{MeOH}$ in different concentrations $(0.5-10 \%, \mathrm{w} / \mathrm{v}), 20 \mu \mathrm{l}$ of $\mathrm{L}$-ascorbic acid $(0.1$ M) and phosphate buffer $(\mathrm{pH}=7.4, I=0.1)$ up to a final volume of $4 \mathrm{ml}$. Samples were incubated $1 \mathrm{~h}$ at $37^{\circ} \mathrm{C}$. Then, $0.2 \mathrm{ml}$ of EDTA $(0.1 \mathrm{M})$ and $1.5 \mathrm{ml}$ of TBA reagent $(3 \mathrm{~g}$ TBA, $120 \mathrm{~g} \mathrm{TCA}$ and $10.4 \mathrm{ml} \mathrm{HClO}_{4}$ in $800 \mathrm{ml}$ of distilled water) were added in each sample and heated for $15 \mathrm{~min}$ at $100^{\circ} \mathrm{C}$. After cooling on ice, samples were centrifugated for $10 \mathrm{~min}$ (3000 rpm) and absorbance of supernatant was measured at $532 \mathrm{~nm}^{29}$ ) Inhibition of LP was calculated the same way as described in DPPH radical assay.

Statistical Analysis One way analysis of variance was used to compare the data, and the values were considered statistically significant at $p<0.05$.

\section{RESULTS}

Total phenolics content and FRAP values for investigated extracts have shown in Table 1. S. anisochila and S. beckeana extracts had the highest polyphenols content (192.16 and $189.67 \mu \mathrm{g}$ catechin equivalent $/ \mathrm{mg}$ ), as well as the highest TAA (1.87 and $1.83 \mu \mathrm{mol} \mathrm{Fe}{ }^{2+} / \mathrm{mg}$, respectively). S. plumosa extract had the least polyphenols $(65.63 \mu \mathrm{g}$ catechin equiva-

Table 1. Total Phenolics Content and FRAP Values for Stachys Extracts

\begin{tabular}{lcc}
\hline \hline Sample & Total phenolics $^{a)}$ & FRAP value $^{b)}$ \\
\hline S. anisochila & 192.16 & 1.87 \\
S. beckeana & 189.67 & 1.83 \\
S. plumosa & 65.63 & 0.46 \\
S. alpina ssp. dinarica & 141.53 & 1.36 \\
L-Ascorbic acid & & 7.41 \\
\hline
\end{tabular}

a) Expressed as $\mu \mathrm{g}$ catechin equivalent/mg dry weigh extract. b) In units $\mu \mathrm{mol}$ $\mathrm{Fe}^{2+} / \mathrm{mg}$ dry weigh extract. 
lent $/ \mathrm{mg})$ and had minimum of TAA $\left(0.46 \mu \mathrm{mol} \mathrm{Fe}{ }^{2+} / \mathrm{mg}\right)$. Correlation between polyphenols content and antioxidant potential of the extracts was found to be high $(r=0.999)$ (Fig. 1). All extracts had TAA lower than L-ascorbic acid used as standard $\left(7.41 \mu \mathrm{mol} \mathrm{Fe}{ }^{2+} / \mathrm{mg}\right)$.

In DPPH assay all extracts showed concentration dependent activity. Concentrations at which etxracts decrease DPPH radical by $50 \%$ ( $\mathrm{IC}_{50}$ values) were $17.90 \mu \mathrm{g} / \mathrm{ml}, 20.90 \mu \mathrm{g} / \mathrm{ml}$, $26.14 \mu \mathrm{g} / \mathrm{ml}$ and $101.61 \mu \mathrm{g} / \mathrm{ml}$ for $S$. anisochila, S. beckeana, $S$. alpina ssp. dinarica and $S$. plumosa extracts, respectively (Table 2). $\mathrm{IC}_{50}$ value for L-ascorbic acid, used as standard, was $4.09 \mu \mathrm{g} / \mathrm{ml}$. Results of DPPH radical assay were also correlated with total phenolics and the results obtained in the FRAP assay (Fig. 2).

Investigated extracts scavenged $\mathrm{OH}$ radical in concentration dependent manner (Table 3 ). In concentration range

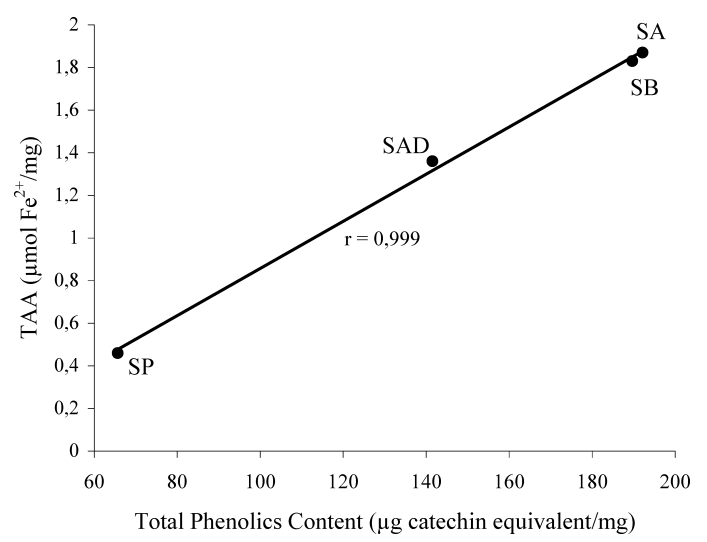

Fig. 1. Values of Total Phenolics Content and Total Antioxidant Activity (FRAP Values) of Stachys Extracts

SP: S. plumosa; SAD: S. alpina ssp. dinarica; SB: S. beckeana; SA: S. anisochila. Results show strong correlation $(r=0.999)$ between the two parameters. from 6.25 to $50 \mu \mathrm{g} / \mathrm{ml}$, all extracts inhibited 2-deoxyribose degradation above $40 \%$, with maximal inhibitions for $S$. anisochila, S. alpina ssp. dinarica and S. beckeana extracts of $50.22 \%, 50.94 \%$ and $64.97 \%$, respectively. Only $S$. plumosa extract achieved maximal activity of $60.67 \%$ at 100 $\mu \mathrm{g} / \mathrm{ml}$. In higher concentrations for all extracts lower activity was observed. $\mathrm{IC}_{50}$ of quercetin, used as reference compound, was $3.1 \mu \mathrm{g} / \mathrm{ml}$.

Inhibition of lipid peroxidation (LP) was also concentration dependent (Table 4). In applied concentration range (from 12.5 to $250.0 \mu \mathrm{g} / \mathrm{ml}$ ), $\mathrm{IC}_{50}$ values for $S$. beckeana and S. alpina ssp. dinarica extracts were 25.07 and $49.00 \mu \mathrm{g} / \mathrm{ml}$, respectively, while $S$. anisochila and $S$. plumosa extracts did not reach $50 \%$ of LP inhibition. Quercetin, used as a standard, reached $50 \%$ of LP inhibition at $0.75 \mu \mathrm{g} / \mathrm{ml}$.

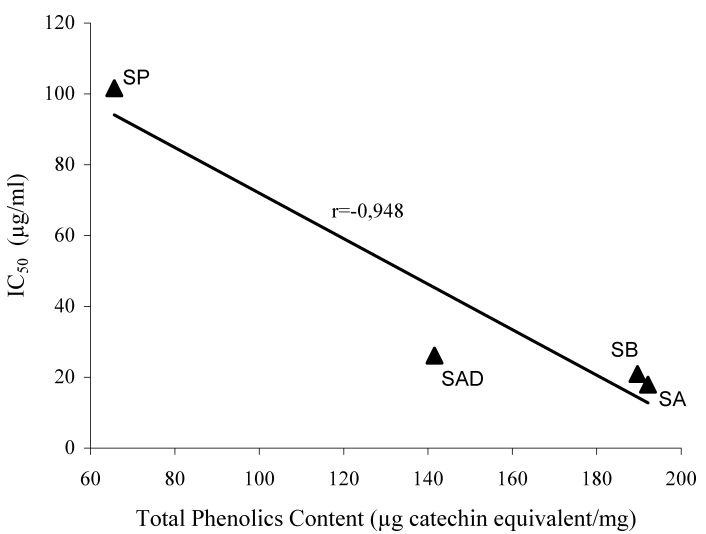

Fig. 2. Values of Total Phenolics Content and DPPH Scavenging $\left(\mathrm{IC}_{50}\right)$ of Stachys Extracts

SP: S. plumosa; SAD: S. alpina ssp. dinarica; SB: S. beckeana; SA: S. anisochila. Results show good correlation $(r=-0.948)$ between the two parameters.

Table 2. Scavenging Effect (\% Inhibition) of Stachys Extracts Obtained in DPPH Radical Assay

\begin{tabular}{|c|c|c|c|c|}
\hline $\begin{array}{l}\text { Concentration of } \\
\text { the extracts }(\mu \mathrm{g} / \mathrm{ml})\end{array}$ & S. anisochila & S. beckeana & S. plumosa & S. alpina ssp. dinarica \\
\hline 5 & $19.71 \pm 1.67$ & $12.88 \pm 1.12$ & $6.22 \pm 0.02$ & $6.82 \pm 1.33$ \\
\hline 10 & $31.97 \pm 0.95$ & $22.76 \pm 0.08$ & $7.80 \pm 0.63$ & $18.18 \pm 0.49$ \\
\hline 20 & $54.56 \pm 1.63$ & $47.87 \pm 0.74$ & $13.24 \pm 0.02$ & $35.57 \pm 0.35$ \\
\hline 50 & $95.33 \pm 0.16$ & $91.66 \pm 1.57$ & $25.73 \pm 0.35$ & $91.60 \pm 0.07$ \\
\hline 100 & $96.24 \pm 0$ & $95.45 \pm 0.08$ & $49.30 \pm 0.18$ & $94.47 \pm 0.42$ \\
\hline 200 & $96.13 \pm 0.04$ & $95.16 \pm 0.17$ & $87.45 \pm 1.06$ & - \\
\hline $\mathrm{IC}_{50}$ & 17.90 & 20.90 & 101.61 & 26.14 \\
\hline
\end{tabular}

Values are expressed as mean of three replications \pm S.D.

Table 3. Scavenging Effect (\% Inhibition) of Stachys Extracts Obtained in 2-Deoxyribose Assay

\begin{tabular}{cccc}
\hline \hline $\begin{array}{c}\text { Concentration of } \\
\text { the extracts }(\mu \mathrm{g} / \mathrm{ml})\end{array}$ & S. anisochila & S. beckeana & S. plumosa \\
\hline 6.25 & $43.50 \pm 2.55$ & $62.64 \pm 0.35$ & $46.87 \pm 0.11$ \\
12.5 & $48.60 \pm 1.72$ & $64.97 \pm 0.01$ & $52.97 \pm 1.36$ \\
25 & $50.22 \pm 1.50$ & $60.99 \pm 2.02$ & $54.25 \pm 2.13$ \\
50 & $47.60 \pm 3.90$ & $58.02 \pm 1.16$ & $58.43 \pm 1.20$ \\
100 & $37.70 \pm 3.76$ & $48.59 \pm 0.12$ & $60.67 \pm 1.25$ \\
200 & $19.70 \pm 3.26$ & $39.17 \pm 1.99$ & $49.94 \pm 0.63$ \\
\hline
\end{tabular}

Values are expressed as mean of three replications \pm S.D. 
Table 4. Inhibitory Effect (\% Inhibition) of Stachys Extracts on Lipid Peroxidation (LP) in Liposomes

\begin{tabular}{|c|c|c|c|c|}
\hline $\begin{array}{l}\text { Concentration of } \\
\text { the extracts }(\mu \mathrm{g} / \mathrm{ml})\end{array}$ & S. anisochila & S. beckeana & S. plumosa & S. alpina ssp. dinarica \\
\hline 12.5 & $21.68 \pm 3.01$ & $41.35 \pm 1.74$ & $30.49 \pm 2.12$ & $4.64 \pm 0.82$ \\
\hline 25.0 & $17.05 \pm 1.22$ & $48.73 \pm 1.94$ & $42.46 \pm 0.29$ & $18.72 \pm 2.21$ \\
\hline 62.5 & $46.02 \pm 3.77$ & $50.70 \pm 0.70$ & $48.73 \pm 0.68$ & $60.49 \pm 4.49$ \\
\hline 125.0 & $37.13 \pm 1.13$ & $53.63 \pm 1.39$ & $36.60 \pm 0.75$ & $69.24 \pm 2.26$ \\
\hline 250.0 & $41.47 \pm 3.27$ & $58.81 \pm 0.03$ & $14.71 \pm 2.98$ & $43.35 \pm 4.25$ \\
\hline $\mathrm{IC}_{50}$ & - & 25.07 & - & 49.00 \\
\hline
\end{tabular}

Values are expressed as mean of three replications \pm S.D.

\section{DISCUSSION}

In previous investigations of Stachys species, presence of various polyphenol compounds was reported. In methanol and ethanol extracts of aerial parts of investigated four species were identified 7-O-glycosides of: apigenin and luteolin $(S$. plumosa $){ }^{31)}$ isoscutelarein $(S$. beckeana, $S$. anisochila, S. plumosa, S. alpina) ${ }^{31-34)}$ hypolaetin (S. beckeana, S. anisochila, S. alpina) ${ }^{31-33)}$ and chrysoeriol (S. plumosa). ${ }^{31)}$ In S. plumosa phenylethanoid glycosides acteoside, martinoside and forsithoside B were found. ${ }^{34)}$ Caffeic, sinapic, protocatechuic, chlorogenic and rosmarinic acids were identified in S. alpina extract. ${ }^{35}$

Some of these compounds were assesed on their antioxidant activity earlier. Acteoside was found to be strong antioxidant, possessing activity comparable to the synthetic antioxidant BHT and clearly superior to natural $\alpha$-tocopherol. ${ }^{36)}$ Martinoside $^{36)}$ and forsithoside $\mathrm{B}^{37)}$ were also strong DPPH scavengers. Phenolic acids exhibited strong DPPH scavenging activity in the following order: rosmarinic $>$ caffeic $>$ chlorogenic $>\alpha$-tocopherol $>$ ferulic acid $>$ BHT. $^{38)}$ Isoscutellarein 7-O-glucoside, along with rosmarinic acid, caused high activity of Rosmarinus officinalis leaf water extract against linoleic acid peroxidation. ${ }^{39}$ ) 8 - $O$-Glucuronides of isocutellarein and hypolaetin possess higher anti-DPPH activity than kempferol. ${ }^{40)}$ Luteolin was also found to be an excellent inhibitor of $\mathrm{Fe}^{3+}$-catalyzed liposome peroxidation, superior in comparison to TBHQ. ${ }^{41)}$

All investigated Stachys extracts exhibited substantial antioxidant activity. High correlations between total phenolics content, TAA and scavenging DPPH radical (Figs. 1, 2, respectively) indicate that polyphenols present in these extracts are the main antioxidants. This is in agreement with previous findings $\mathrm{s}^{37,42,43)}$ and results of TLC analysis obtained in this work. Namely, TLC chromatograms of all four extracts have shown presence of several polyphenol compounds, identified as flavonoids and phenolic acids. With DPPH reagent few yellow spots appeared immediately after the TLC plate had been sprayed, while others revealed during $30 \mathrm{~min}$ period and later. Comparison of obtained chromatograms showed that main spots, identified as flavonoids, are in fact the most potent scavengers of DPPH.

Though inhibition of DPPH radical was obtained in higher concentrations comparing to L-ascorbic acid, all investigated extracts, with the exception of $S$. plumosa, exhibited high anti-DPPH activity $\left(\mathrm{IC}_{50}<50 \mu \mathrm{g} / \mathrm{ml}\right) .{ }^{30}$

As for inhibition of $\mathrm{OH}$ radical and LP, generally all extracts exhibited substantial scavenging activity, though weaker than quercetin used as standard. These effects were more pronounced at lower concentrations of the extracts applied, giving inverted U-shaped concentration-response curve. This could be explained with pro-oxidative effects, phenomena observed for plant extract and polyphenols earlier. ${ }^{5,45}$ In addition, differences among extracts could be also explained by differences in content and type of polyphenols present in investigated extracts, considering complex mechanisms of $\mathrm{OH}$ and hydroperoxyl radicals generation.

Acknowledgements This research was partly supported by the Grant No 1568, Ministry of Science and Environmental Protection, Republic of Serbia.

\section{REFERENCES}

1) Pietta P. G., J. Nat. Prod., 63, 1035-1042 (2000).

2) Arouma O. I., J. Am. Oil Chem. Soc., 75, 199-212 (1998).

3) Ratty A. K., Sunamoto J., Das N. P., Biochem. Pharmacol., 37, 989995 (1983).

4) Mora A., Payá M., Ríos J. L., Alcaraz M. J., Biochem. Pharmacol., 40, $793-797$ (1990).

5) Lee J.-C., Kim J., Park J.-K., Chung G.-H., Jang Y.-S., Exp. Cell Res., 291, 386-397 (2003).

6) Grieve M., "A Modern Herbal," Dover Publications, Inc., New York, 1971, pp. 97, 862.

7) Hoppe H., "Drogekunde," Garm de Gruyter and Co., Hamburg, 1958, pp. $859-860$.

8) Maleki N., Garjani A., Nazemiyeh H., Nilfouroushan N., Eftekhar Sadat A. T., Allameh Z., Hasannia N., J. Ethnopharmacol., 75, 213218 (2001).

9) Khanavi M., Sharifzadeh M., Hadjiakhoondi A., Shafiee A., $J$ Ethnopharmacol., 97, 463-468 (2005).

10) Skaltsa H. D., Lazari D. M., Chinou I. B., Loukis A. E., Planta Med., 65, 255-256 (1999).

11) Skaltsa H. D., Demetzos C., Lazari D., Sokovic M., Phytochemistry, 64, 743-752 (2003).

12) Hayashi K., Nagamatsu T., Ito M., Hattori T., Suzuki Y., Jpn. J. Pharmacol., 65, 143-151 (1994).

13) Hayashi K., Nagamatsu T., Ito M., Hattori T., Suzuki Y., Jpn. J. Pharmacol., 66, 47-52 (1994).

14) Hayashi K., Nagamatsu T., Ito M., Yagita H., Suzuki Y., Jpn. J. Pharmacol., 70, 157-168 (1996).

15) Rabbani M., Sajjadi S. E., Zarei H. R., J. Ethnopharmacol., 89, 271276 (2003).

16) Couladis M., Tzakou O., Verykokidou E., Harvala C., Phytother. Res., 17, 194-195 (2003).

17) Mantle D., Eddeb F., Pickering A. T., J. Ethnopharmacol., 72, 47-51 (2000).

18) Meremeti A., Karioti A., Skaltsa H., Heilmann J., Sticher O., Biochem Syst. Ecol., 32, 139-151 (2004).

19) Ball P. W., "Flora Europaea," Vol. IV, ed. by Tutin T. G., Heywood V. H., Burges N. A., Moore D. M., Valentine D. H., Walters S. M., Webb D. A., University Press, Cambridge, 1976, pp. 151-157.

20) Diklić N., "The Flora of FR Serbia," Vol. VI, ed. by Josifović M., Serbian Academy of Sciences and Arts, Department of Natural and Mathematical Sciences, Belgrade, 1974, pp. 408-432. 
21) Koeva I., "Flora Reipublicae Popularis Bulgaricae," Vol. IX, ed. by Jordanov D., Velćev V., Kuzmanov B., Academia Scientiarum Bulgaricae, Sofia, 1989, pp. 388-410.

22) Wagner H., Bladt S., "Plant Drug Analysis. A Thin Layer Chromatography Atlas," 2nd ed., Springer-Verlag, Berlin-Heidelberg, 1996, pp. 196-197.

23) Takao T., Kitatani F., Watanabe N., Yagi A., Sakata K., Biosci. Biotechnol. Biochem., 58, 1780-1783 (1994).

24) Cuendet M., Hostettmann K., Potterat O., Helv. Chim. Acta, 80, 1144-1152 (1997).

25) Velioglu Y. S., Mazza G., Gao L., Oomah B. D., J. Agric. Food Chem., 46, 4113-4117 (1998).

26) Szöllösi R., Szöllösi Varga I., Acta Biol. Szeged., 46, 125-127 (2002).

27) Luximon-Ramma A., Bahorun T., Soobrattee M. A., Aruoma O. I., $J$ Agric. Food Chem., 50, 5042-5047 (2002).

28) Lee J.-C., Lim K.-T., Food Sci. Biotechnol., 9, 83-88 (2000).

29) Afanas'ev I. B., Dorozhko A. I., Brodskii A. V., Kostyuk V. A., Potapovitch A. I., Biochem. Pharmacol., 38, 1763-1769 (1989).

30) Cho E. J., Yokozawa T., Rhyu D. Y., Kim S. C., Shibahara N., Park J. C., Phytomedicine, 10, 544-551 (2003).

31) Marin P. D., Grayer R. J., Grujic-Jovanovic S., Kite G. C., Veitch N. C., Phytochemistry, 65, 1247-1253 (2004).

32) Lenherr A., Meier B., Sticher O., Planta Med., 50, 403- 409 (1984).

33) Lenherr A., Mabry T. J., Phytochemistry, 26, 1185-1188 (1987).
34) Bankova V., Koeva-Todorovska J., Stambolijska T., Ignatova-Groceva M.-D., Todorova D., Popov S., Z. Naturforsch. C, 54, 876-880 (1999).

35) Buchwald W., Czapska A., Herba Polonica, 41, 198-202 (1995).

36) Aligianis N., Mitaku S., Tsitsa-Tsardis E., Harvala C., Tsaknis I., Lalas S., Haroutounian S., J. Agric. Food Chem., 51, 7308-7312 (2003).

37) Delazar A., Sarker S. D., Shoeb M., Kumarasamy Y., Nahar L., Nazemyieh H., Iranian J. Pharm. Res., Supp., 2, 23-24 (2004).

38) Chen J. H., Ho C.-T., J. Agric. Food Chem., 45, 2374-2378 (1997).

39) del Baňo M. J., Lorente J., Castillo J., Benavente-García O., del Río J. A., Ortuňo A., Quirin K.-W., Gerard D., J. Agric. Food Chem., 51, 4247-4253 (2003).

40) Yang H., Protiva P., Cui B., Ma C., Baggett S., Haquet V., Mori S., Weinstein I. B., Kennelly E. J., J. Nat. Comp., 66, 1501-1504 (2003).

41) Arora A., Nair M. G., Strasburg G. M., Free Rad. Biol. Med., 24, 1355-1363 (1998).

42) Benzie I. F. F., Szeto Y. T., J. Agric. Food Chem., 47, 633-636 (1999).

43) Yildirim A., Mavi A., Kara A. A., J. Agric. Food Chem., 49, 40834089 (2001).

44) Schlesier K., Harwat M., Bohm V., Bitsch R., Free Rad. Res., 36, 177-187 (2002)

45) Laughton M., Halliwell B., Evans P. J., Hoult J. R. S., Biochem. Pharmacol., 38, 2859-2865 (1989). 